\title{
One Fish, Two Fish, Red Fish, Blue Fish: Geography, Ecology, Sympatry, and Male Coloration in the Lake Malawi Cichlid Genus Labeotropheus (Perciformes: Cichlidae)
}

\author{
Michael J. Pauers \\ Section of Vertebrate Zoology, Milwaukee Public Museum, 800 West Wells Street, Milwaukee, WI 53233, USA \\ Correspondence should be addressed to Michael J. Pauers, mjpauers@gmail.com
}

Received 15 November 2010; Revised 15 February 2011; Accepted 28 March 2011

Academic Editor: Kristina M. Sefc

Copyright () 2011 Michael J. Pauers. This is an open access article distributed under the Creative Commons Attribution License, which permits unrestricted use, distribution, and reproduction in any medium, provided the original work is properly cited.

\begin{abstract}
While sexual selection on male coloration has been important in haplochromine cichlid speciation, few studies to date have examined potential environmental influences on color pattern evolution. Data from multiple sources on male nuptial coloration of the Lake Malawi endemic genus Labeotropheus were used to examine the relationship between color patterns and the environments in which these patterns were found. Red- or carotenoid-pigmented males were concentrated in the northwestern portion of Lake Malawi and were also associated with increasing depth. Further, the presence or absence of L. fuelleborni influenced the coloration of L. trewavasae populations; when L. fuelleborni was present, L. trewavasae males were more likely to exhibit some degree of red coloration. While these results support the idea that sexual selection on male coloration is an important factor in the haplochromine speciation, they also underscore the importance of environmental influences on the evolution of color patterns.
\end{abstract}

\section{Introduction}

An organism's color can serve an adaptive function in numerous ecological contexts, including crypsis, communication, and thermoregulation $[1,2]$. As such, it is likely that organismal color reflects a balance among numerous and perhaps competing demands; a color best suited for the performance of one function (e.g., cryptic avoidance of predators) may reflect a trade-off with that suited for another (e.g., attractiveness to potential mates). This tradeoff is further shaped by the wavelengths of light available in the organism's natural environment; a color pattern that is cryptic in one environment may be conspicuous in another $[1,3-5]$. In other words, the relative strength of the color signal depends on not only the visual system of the receiver but also the medium and surrounding environment in which it is transmitted $[3,6,7]$.

This trade-off is especially important in aquatic environments, where the available wavelengths of visible (and nearvisible) light are highly habitat dependent, thus potentially placing a limit on the palette of colors available to the organisms that live there [7-10]. The background against which the color patterns of aquatic organisms are typically viewed will also further constrain the efficiency of certain visual signals $[2,4,7,8,11]$. Because of these limitations on the spectral environment of aquatic systems and their potential effects on organismal color, aquatic organisms are excellent choices for studying the interactions of environment or ecology and the evolution of color patterns.

The bright colors of male haplochromine cichlids have received much attention from evolutionary biologists. These colors caused early researchers to speculate that sexual selection may have played an important role in African cichlid speciation $[12,13]$, an idea that was later confirmed in several lab and field studies [14-17]. Indeed, it has even been proposed that sexual selection via female choice is solely responsible for the evolution of these color patterns, with little or no role allowed for the effects of ecological and environmental context $[18,19]$. And, despite the early attention paid to female choice, several researchers found evidence that male intrasexual interactions may play a role in the diversification of color patterns among haplochromine species. Pauers et al. [17], working with several Lake Malawi species, performed a laboratory study in which they found 
that males were more aggressive towards similarly colored opponents, whether or not they were of the same genus. Further, Seehausen and Schluter [20] and Young et al. [21] found that the membership of communities of Lake Victoria and Lake Malawi species was dictated by male coloration; in both lakes, communities of cichlids were more likely to be composed of species in which the males were differently colored from one another.

Despite this, the evidence regarding the relationship between color (or color pattern) and environment has been equivocal. For example, Goldschmidt [22] demonstrated that the size of anal fin egg spots and, to a lesser extent, egg spot number, increase with decreasing light intensity in Lake Victorian haplochromines. McElroy et al. [23] and Deutsch [18] took spectral measurements from published pictures of Lake Malawi haplochromines and looked for patterns among coloration and environment. While Mc Elroy et al. [23] found some statistically significant correlations, mostly in terms of substrate preference and diet, Deutsch [18] found no significant relationships between male color and ecology, attributing color diversity instead to sexual selection via female choice. Seehausen et al. [19] examined gross color pattern type among all lineages of African cichlids and mapped these color characteristics on a phylogenetic tree. The resulting phylogenetic associations between color pattern elements and ecology indicated that while various stripe patterns had strong ecological associations, male nuptial coloration concomitantly originated with the evolution of promiscuous mating systems in East African cichlids; further, male nuptial coloration may have evolved in a direct response to female mate choice.

Additionally, two more recent, largely field-based studies also drew contrasting conclusions regarding the relationships among male nuptial coloration and the spectral environment. Seehausen et al. [24] found that at populations of a polychromatic Lake Victorian haplochromine in which there was a moderate spectral gradient between shallow and deep habitats, there was a distinct gradient of male coloration, with blue males inhabiting the shallows and red males living at deeper depths. On the other hand, at populations in which there was a steep spectral gradient, the variation among nuptial color types was muted and no clear pattern was found. Interestingly, patterns of female mate choice closely followed these patterns of male nuptial color. Dalton et al. [25] found that among cichlid species within a single Lake Malawi location, there was no relationship between any aspect of male coloration and any feature of the environment, including depth.

Further complicating our understanding of the relationship between color and environment is the relationship between cichlid visual sensitivity and the environment. In an important early study, Muntz [26] found that Lake Malawi cichlids had different complements of visual pigments depending upon the depths at which they live. This was confirmed for African cichlids in general by Spady et al. [27], who found that cichlids from clear habitats expressed different photopigments or differently tuned versions of the same photopigments; this was also found in Lake Victorian cichlids by Terai et al. [28] and Carleton et al. [29].
Furthermore, there is evidence that turbidity constricts male cichlid coloration to those colors that best match or contrast with the surroundings. Lake Malawi is a clear, bright lake and tends to have fish with predominantly blue and yellow coloration. Lake Victoria, being more turbid, tends to have more fish with red and green pigments [18, 23-25]. Given this, it is reasonable to expect that changes in light at various depths could constrain male nuptial coloration (but see Dalton et al. [25]).

The African cichlid genus Labeotropheus (Ahl 1927; [30]) is one of the rock-dwelling haplochromine "mbuna" endemic to Lake Malawi. It contains two recognized species, L. fuelleborni and L. trewavasae. L. fuelleborni is a deepbodied, shallow-dwelling algae scraper often found in association with large rocks, while L. trewavasae is a slenderbodied, deeper-dwelling algae scraper that prefers the bottoms and sides of smaller rocks $[31,32]$. Despite these differences in ecology, the two species share a cosmopolitan distribution throughout the lake, as well as differing male nuptial colors among populations [31-34]. Further, while L. fuelleborni and L. trewavasae may be found at the same location, the males of these species very rarely have similar nuptial colorations when found in sympatry $[33,34]$. As with many other mbuna populations, Labeotropheus populations are isolated from each other by a combination of habitat discontinuities and behavioral mechanisms, so it is likely that there is very little, if any, gene flow among them $[31,32,35]$.

Lake Malawi is a large and heterogeneous lake, which suggests that isolated populations of Labeotropheus may experience unique visual environments that could influence the evolution or development of their visual systems [24, $31,36]$. Since both intra- and intersexual selection have been demonstrated to play important roles in the evolution of male nuptial coloration in the mbuna in general and in the Labeotropheus in particular $[15,16,37]$, differing spectral environments among populations could, in turn, have an effect on male nuptial coloration. Thus, the analysis described below is an attempt to explore possible relationships among environmental features of Labeotropheus populations and male nuptial coloration and to explore the relative contributions of natural and sexual selection to the evolution of male color patterns in the Labeotropheus.

\section{Methods}

2.1. Data Collection. Pictures or descriptions of Labeotropheus color patterns were obtained from six sources [31$33,38-40]$. The information from all five sources was sufficient to classify each Labeotropheus populations as one of Seehausen et al.'s [41] three general haplochromine nuptial color pattern types: Blue, Red Dorsal, or Red Ventral (Table 1). In applying these color categories to Lake Malawi cichlids, it should be noted that the adjective "red" refers to carotenoid pigmentation in general, including hues of orange, yellow, and ochre, as there are very few examples of pure red coloration in these fishes [23, 41]. In addition, I further classified fish based on the pigment ("Red" or Blue) that colored the majority (i.e., greater than $50 \%$ ) of the 
body of the fish, excluding the fins. This was done for two reasons. First, I wanted to separate coloration that might be more influenced by environmental factors (i.e., the trunk of the fish) from that which might be more influenced by female mate choice (i.e., the fins). For example, a common color pattern in Lake Malawi cichlid fishes is a version of Red Dorsal in which the entire body of the fish is blue and only the dorsal fin is red (Table 1). While swimming, with the median fins clamped closely to the body, this fish may appear to other organisms to be entirely blue; however, when engaged in display activity, whether warding off a competitor or attempting to attract potential mates, its full color pattern is visible. Secondly, I wanted to control for the degree to which a particular population expresses one of these nuptial color types (e.g., both a blue-bodied fish with a red dorsal fin and a red-bodied fish with a white belly are considered Red Dorsal under this classification; Table 1).

Two sources $[31,32]$ provided information on the minimum, modal, and maximum depths observed, gross habitat type (mainland, island, or rock/reef) and latitude/longitude for some populations of Labeotropheus ( $n=35)$. Konings [39] was useful in determining some habitat types and latitude/longitude for some additional populations $(n=36)$. For populations where direct information was not available, depths were estimated based on species and habitat type. These depth estimations are reasonable because Ribbink et al. [32] demonstrate that Labeotropheus populations tend to have characteristic depth distributions based on both species and gross habitat type. Mainland populations of either species tend to be shallower than island populations, which are shallower than rock/reef populations (see [32, Figure 3, Page 228]). Therefore, those populations for which depth information was unavailable $(n=43)$ were assigned the mean values of minimum, modal, and maximum depths for populations of the same species occurring at the same type of habitat, making habitat type a satisfactory surrogate for depth.

It should be further noted that, in the descriptions and discussions that follow, when I refer to any category (minimum, maximum, or modal) of depth, what I am actually referring to is the depth at which Labeotropheus are found.

Data were compiled with separate entries for each species at each location. The data included information on male nuptial, body color, and environmental information (depth, latitude, longitude, habitat type, and whether one or both species of Labeotropheus were present at a given location).

2.2. Statistical Analyses. The data were analyzed using a multivariate general linear model in the Set Correlation module in Systat (v. 10.0) [42, 43]. The data were subdivided into two distinct sets; data regarding the fish themselves (species, nuptial color, and body color) were considered to be one set, while the environmental parameters (depth, latitude, longitude, habitat type, and presence of one or both Labeotropheus species) were considered to be another. Using the fish data as a set of dependent variables and the environmental data as a set of independent variables,
I looked for patterns of correlation and predictability both within and between these sets with Set Correlation. The Set Correlation module provides two types of output: (1) basic correlations among variables both within and between sets and (2) a regression of the independent set against the dependent set, in order to find possible predictive relationships among the variables. Further, a categorical variable with $n$ possible states was collapsed into $n$ - 1 factors using a Canonical Correlation Analysis [43]; thus, nuptial color, with three possible states (Blue, Red Dorsal, and Red Ventral), was collapsed into two factors, identified as Nuptial Color (1) and Nuptial Color (2), respectively.

Within the independent set, habitat type was collapsed into two distinct habitat factors based on differences in Labeotropheus depth and geographical distribution. While Systat does not identify the particular habitat most strongly associated with these factors, examining the depth and geographical factors that have the highest correlations with each habitat can identify the habitats designated as Habitat (1) and Habitat (2), respectively; this same approach can identify the dependent factors as well. In the dependent set, nuptial color yielded two separate nuptial color factors and body color was reduced into a single factor. Further, the two species of Labeotropheus were similarly reduced to a single species factor.

Correlations between the dependent and independent sets were used to determine which color patterns were associated with which environmental variables. Identification of predictive relationships between sets was accomplished by evaluating the standardized regression coefficients and their respective $P$ values for relationships among variables between the dependent and independent sets. Canonical correlations between sets were generated from the rotated canonical factors for both the independent and dependent sets.

Because of the estimation process used to generate some of the depth data, I used the semipartial correlation of known versus estimated depth data type with the independent set of variables, yielding an X semipartial correlation [43]. Partialling, which is a generalization of residualization procedures common to multiple regression and correlation, allows one or more variables to be "partialled out" of either (or both) the dependent or independent sets, thus creating a new set (or sets) in which the variables have zero correlations with the original set (or sets) [42]. This procedure helps to minimize any possible spurious effects of the estimation of depth data and has the further effect of reducing error variance, thus increasing statistical power $[42,43]$. In this case, the Systat created a dummy variable for depth data type, giving a value of 1 or 0 for known or estimated data, respectively, and then performed the partialization on the independent set [43]. Thus, partialling the independent set by the type of depth data removed any effects of estimating the depths of the various Labeotropheus populations.

\section{Results}

The overall analysis is significant and robust (Rao's $F_{32,219.2}$ $=5.459 ; P \leq .001)$ and only slightly affected by shrinkage $\left(R^{2}=0.881\right.$; shrunk $\left.R^{2}=0.803\right)$. 
TABLe 1: Possible nuptial color and body color combinations in Labeotropheus. Photos generously provided by Ad Konings/Cichlid Press.

\begin{tabular}{|c|c|c|c|c|}
\hline \multirow{2}{*}{$\begin{array}{l}\text { Nuptial color } \\
\text { pattern }\end{array}$} & \multirow{2}{*}{$\begin{array}{l}\text { Possible body } \\
\text { color }\end{array}$} & \multirow{2}{*}{ Example } & \multicolumn{2}{|c|}{ Number of populations } \\
\hline & & & L. fuelleborni & L. trewavasae \\
\hline \multirow[t]{2}{*}{ Blue } & Blue & & 25 & 14 \\
\hline & Blue & & 4 & 8 \\
\hline \multicolumn{5}{|l|}{ Red Dorsal } \\
\hline & Red & & 1 & 10 \\
\hline & Blue & & 1 & 0 \\
\hline \multicolumn{5}{|l|}{ Red Ventral } \\
\hline & Red & & 5 & 4 \\
\hline
\end{tabular}

3.1. Within-Independent Set Correlations: Habitat Type Discrimination. The within-independent set correlations are presented in Table 2. Habitat (1) is moderately and negatively correlated with latitude and longitude and strongly and negatively correlated with minimum depth, suggesting a habitat type with a northwestern bias in its distribution at which Labeotropheus are found at relatively shallow depths. Figures 1(a) and 1(b) demonstrate that mainland populations of Labeotropheus are more prevalent in the northern and northwestern portion of the lake than island or rock/reef habitats and that, as found by Ribbink et al. [32], these mainland populations have the shallowest distributions of Labeotropheus; thus, Habitat (1) is indicative of mainland habitats. Habitat (2) has strong, positive correlations with all three measures of Labeotropheus population depth. This association with depth suggests that the habitat with the deepest distribution of Labeotropheus is identified by Habitat (2); therefore, this factor identifies rock/reef habitats (Figure 1(b)).

3.2. Within-Dependent and Between-Set Correlations: Identification of Species and Color Pattern. The identification of species, nuptial color patterns, and body color identified
TABLE 2: Identification of habitat type (Mainland, Island, or Rock/ Reef) from within-independent set correlations; informative values bolded.

\begin{tabular}{lcc}
\hline & Habitat (1) & Habitat (2) \\
\hline Latitude & $\mathbf{- 0 . 2 7 9}$ & 0.050 \\
Longitude & $-\mathbf{0 . 2 2 6}$ & 0.050 \\
Minimum depth & $-\mathbf{0 . 4 7 1}$ & $\mathbf{0 . 5 4 9}$ \\
Maximum depth & -0.127 & $\mathbf{0 . 4 3 5}$ \\
Modal depth & -0.237 & $\mathbf{0 . 5 5 0}$ \\
Number of Labeotropheus species & 0.008 & -0.06 \\
\hline
\end{tabular}

by the Set Correlation procedure requires both the withindependent and between-set correlations, as some of the correlations for a given factor are stronger in one type of correlation versus the other; this is especially the case with the nuptial color factors.

Table 3 contains the between-set correlations, which are helpful in identifying both the species and body color factors. The species factor, Species (1), shows a strong, positive association with depth; thus, L. trewavasae is the Labeotropheus identified by this factor. Body Color (1) is 


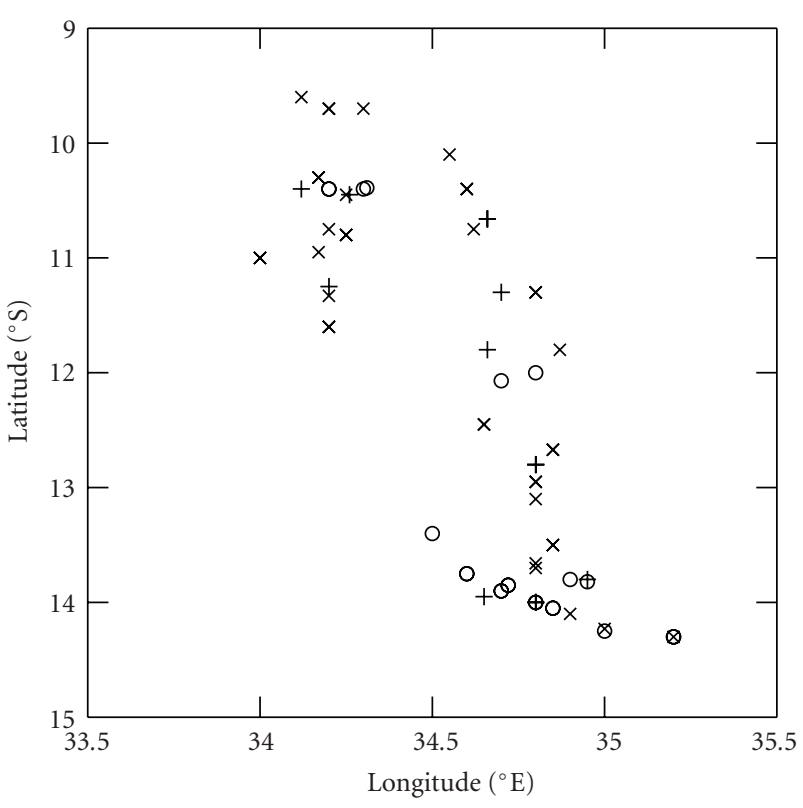

Habitat type
$\times$ Island
$\times$ Mainland

+ Rock/reef

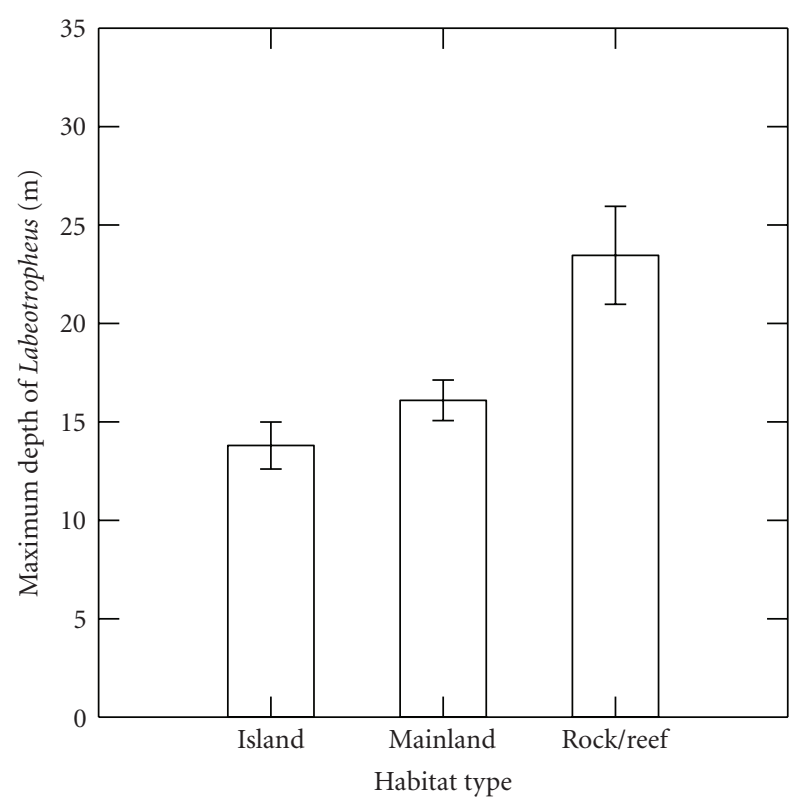

(a)

(b)

FIGURE 1: Within-independent set correlations and habitat type identification. (a) Geographic distribution of habitats at which Labeotropheus populations are found in Lake Malawi. (b) Maximum depths at which Labeotropheus populations are found at each habitat type.

strongly and negatively correlated with both longitude and latitude, suggesting a northwestern bias in the distribution of this coloration. Red body color displays this kind of geographic distribution (Figure 2(a)); thus, Body Color (1) represents Red body coloration.

Both nuptial color factors have slight to moderately negative correlations with longitude and latitude, suggesting a northwestern bias in their distributions; this is especially the case for Nuptial Color (2) (Table 3). Also, as shown in the within-dependent set correlations (Table 4), both have a strong correlation with Body Color (1), suggesting that they are comprised of mostly carotenoid pigmentation. Further, the strong correlation between Nuptial Color (1) and Species (1) indicates that it is most common in L. trewavasae. As shown in Figure 2(b), the most common male color pattern in L. trewavasae is Red Dorsal; thus, Red Dorsal is the color pattern identified by Nuptial Color (1). Figure 2(c) displays the geographic distributions of Labeotropheus color patterns, and the pattern with the most distinct northwestern bias in its distribution is Red Ventral; Nuptial Color (2) identifies the Red Ventral pattern.

3.3. Regression Analysis: Predictive Relationships. The results of the regression analyses show that Species (1), Nuptial Color (1), and Body Color (1) have significant relationships predicted by at least one of the independent variables; none of the relationships involving Nuptial Color (2) and any of the independent variables are significant (Table 5).
Species (1), which represents L. trewavasae, has significant relationships with all measures of depth and Habitat (2). The signs of the coefficients for minimum depth and Habitat (2) are negative, while those for maximum depth and modal depth are positive, suggesting that $L$. trewavasae is found most often at deeper, mainland habitats (Figure 3(a)).

Body Color (1), representing Red body coloration, also has a significant and positive relationship with depth (Figure 3(b)). Further, Body Color (1), as the between-set correlations above demonstrate, has a significant, negative relationship with latitude, suggesting a northern bias in its distribution (see Figure 2(a)). Nuptial Color (1), representing the Red Dorsal nuptial color pattern, has significant, positive relationships with maximum depth (Figure 3(c)) and with the number of Labeotropheus species present at a given location (Figure 4).

\section{Discussion}

The set correlation analysis performed on the Labeotropheus biogeographical dataset recovered several correlations between coloration and environment, as well as some predictive relationships among the color and environmental variables. The correlations found included correlations between $L$. trewavasae and depth, Red Dorsal nuptial coloration and depth, and a correlation between a northwestern geographical distribution and both Red Ventral nuptial coloration and Red body coloration. The regression analysis 
TABLE 3: Between-set correlations; informative values bolded.

\begin{tabular}{lcccc}
\hline & Species (1) & Nuptial Color (1) & Nuptial Color (2) & Body Color (1) \\
\hline Latitude & -0.247 & -0.039 & $-\mathbf{0 . 3 4 0}$ & $-\mathbf{0 . 4 6 6}$ \\
Longitude & -0.200 & -0.060 & $-\mathbf{0 . 3 0 6}$ & $-\mathbf{0 . 3 8 3}$ \\
Minimum depth & 0.308 & -0.074 & -0.056 & -0.082 \\
Maximum depth & $\mathbf{0 . 7 6 8}$ & $\mathbf{0 . 2 6 7}$ & $-\mathbf{0 . 1 6 1}$ & 0.135 \\
Modal depth & $\mathbf{0 . 7 3 7}$ & 0.155 & -0.095 & 0.029 \\
Habitat (1) & 0.126 & 0.089 & 0.049 & $\mathbf{0 . 2 4 9}$ \\
Habitat (2) & 0.097 & -0.003 & -0.101 & -0.171 \\
Number of Labeotropheus species & 0.007 & 0.190 & -0.118 & -0.049 \\
\hline
\end{tabular}

TABLE 4: Within-independent set correlations; informative values bolded.

\begin{tabular}{lcccc}
\hline & Species (1) & Nuptial Color (1) & Nuptial Color (2) & \\
\hline Species (1) & 1.000 & & & \\
Nuptial Color (1) & $\mathbf{0 . 3 8 7}$ & 1.000 & 1.000 & $\mathbf{0 . 5 5 8}$ \\
Nuptial Color (2) & -0.080 & -0.275 & $\mathbf{0 . 3 0 7}$ & 1.000 \\
Body Color (1) & $\mathbf{0 . 2 4 8}$ & & \\
\hline
\end{tabular}

also recovered the relationships between $L$. trewavasae and depth, as well as those between both geography and depth and Red body coloration. The most interesting result of the regression analysis, however, is the predictive relationship between Red Dorsal nuptial coloration and sympatry of the Labeotropheus species; when found at the same location, the males of the deeper-dwelling L. trewavasae adopt a Red Dorsal nuptial color pattern.

It is not surprising that this analysis recovered the welldocumented relationship between $L$. trewavasae and depth; L. trewavasae is found most frequently at and prefers water depths of typically more than 15 meters [32]. On the other hand, the disjoint geographical distribution of color patterns in Labeotropheus is interesting, with red-pigmented populations concentrated in the northwestern portion of Lake Malawi; a similar pattern of geographic bias in male nuptial color types has been found in the Metriaclima [44]. This suggests two possible explanations. First, it may be that natural or sexual selection favors red-/carotenoid-pigmented individuals in the northwest part of the lake; the spectral properties of the water and backgrounds in this area of Lake Malawi could possibly favor reddish coloration for crypsis or communication. There is some corroborating evidence for this possibility, as the northern portion of Lake Malawi experiences a significant amount of rainfall, so the nearshore waters here could be more turbid than in other parts of the lake (H. Bootsma, pers. comm.). Thus, the abundance of reddish Labeotropheus in this region would be expected, as African cichlids in more turbid environments display more red coloration in their nuptial coloration $[18,23]$. A second possibility for the disjoint geographical distribution of color patterns in Labeotropheus is that the populations clustered within either the northwestern or more southern regions of the lake could be more closely related to each other than to populations from the other region. Recent investigations of genetic relatedness among populations suggest that this may be the case $[35,44]$, though there is some evidence to the contrary $[44,45]$. In order to address these two hypotheses regarding the distribution of male coloration, investigations of habitat light and background color (e.g., $[8,25])$, and geographic patterns of genetic relatedness (sensu [35]), should be carried out on the Labeotropheus populations in these portions of Lake Malawi.

Further, the regression analysis revealed that Red Dorsal nuptial coloration is also significantly and positively related with increasing maximum depth, as was Red body coloration. Red body coloration was also found to have a significant, negative relationship with latitude, suggesting that it has a northern bias in its distribution in Lake Malawi. While the implications of a geographical bias in the distribution of male nuptial coloration in the Labeotropheus were discussed in the preceding paragraph, the association between color and depth merits further consideration. Lake Malawi is a very clear lake; even so, long wavelength light acutely attenuates between 0 and 10 meters of depth, which is much shallower than the maximum depths recorded for populations of L. fuelleborni, as well as the maximum or modal depths of many populations of $L$. trewavasae $[31,32]$. Thus, it seems paradoxical that fish with red or orange coloration should be found where the strength of this signal would be constrained. Recent research by Dalton et al. [25] suggests that, despite the limited amount of long-wavelength light at these depths, the mbuna visual system allows for a surprising degree of color constancy, thus seeming to permit red- or carotenoid-pigmented fish to live in areas where their coloration would otherwise be obscured. Further, Dalton et al. [25] found that in one population of L. trewavasae, the coloration of both male and female fish is conspicuous against all possible backgrounds in their environment, suggesting that the saturation of colors on the fish may also aid in their visibility.

Perhaps the key finding of the regression analysis is the significant, positive relationship between the number of species of Labeotropheus present at a given location and 

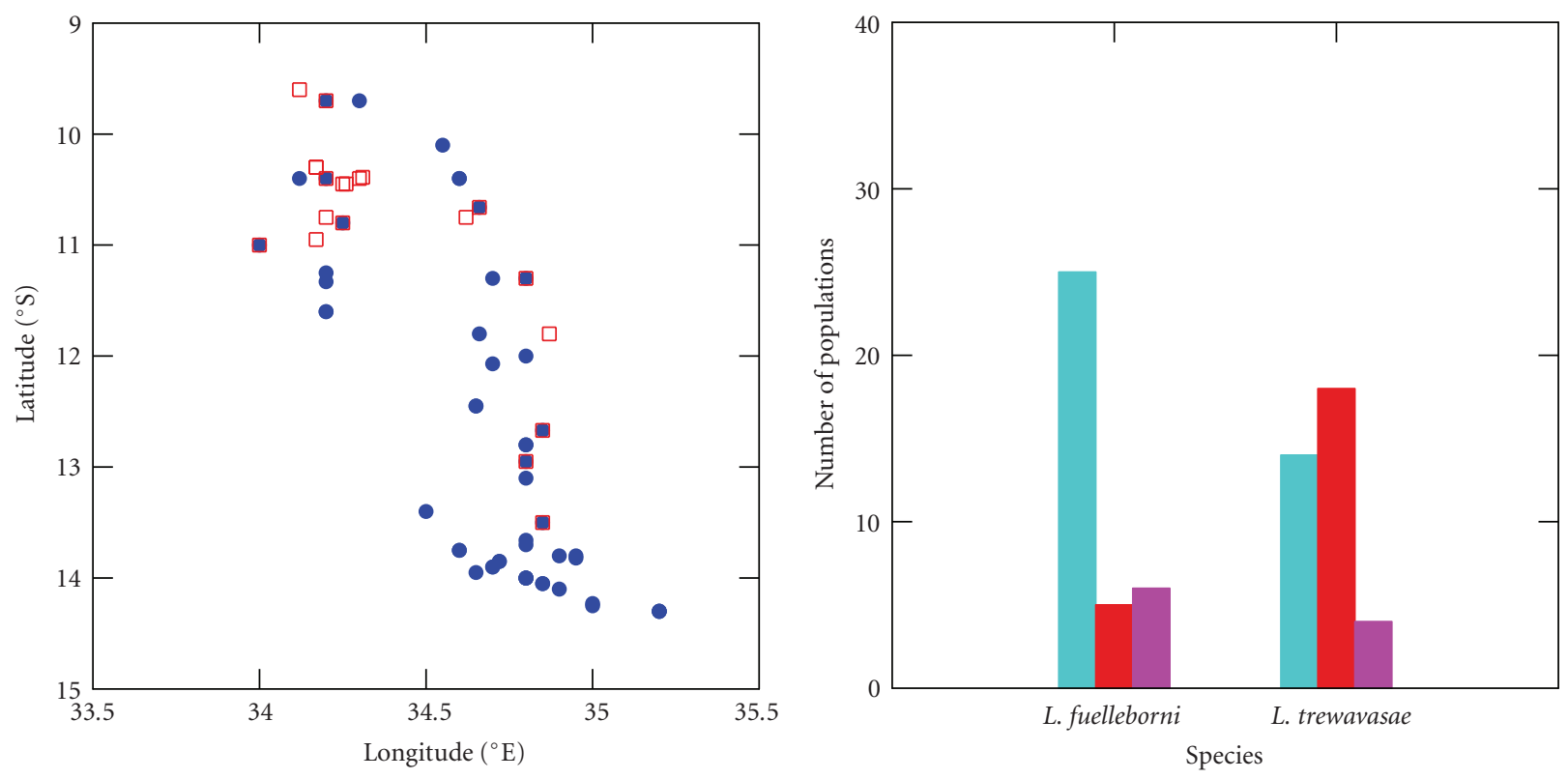

Body color

- Blue

Nuptial color

Blue

Red Ventral

$\square$ Red

(a)

(b)

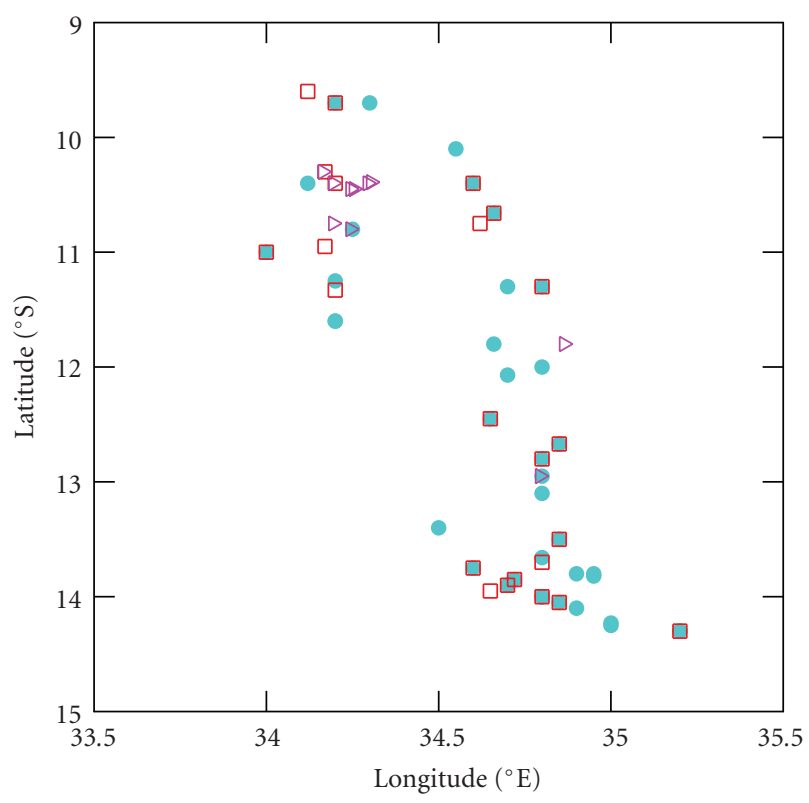

Nuptial color

- Blue

$\triangleright$ Red Ventral

$\square$ Red Dorsal

(c)

Figure 2: Between-set correlations and identification of nuptial and body color factors. (a) Geographic distribution of Labeotropheus body color types in Lake Malawi. (b) Frequency of nuptial color types in L. fuelleborni and L. trewavasae. (c) Geographic distribution of Labeotropheus nuptial color types in Lake Malawi.

Red Dorsal male nuptial coloration. When both species of Labeotropheus are present, one of them adopts a Red Dorsal color pattern. Interestingly, as shown in Figure 4(b), it is the deeper-dwelling $L$. trewavasae that adopts this pattern when found in sympatry with L. fuelleborni. While it has been previously noted that, when sympatric, the Labeotropheus tends to adopt different nuptial coloration [33]; this is the first time this relationship has been confirmed quantitatively. 


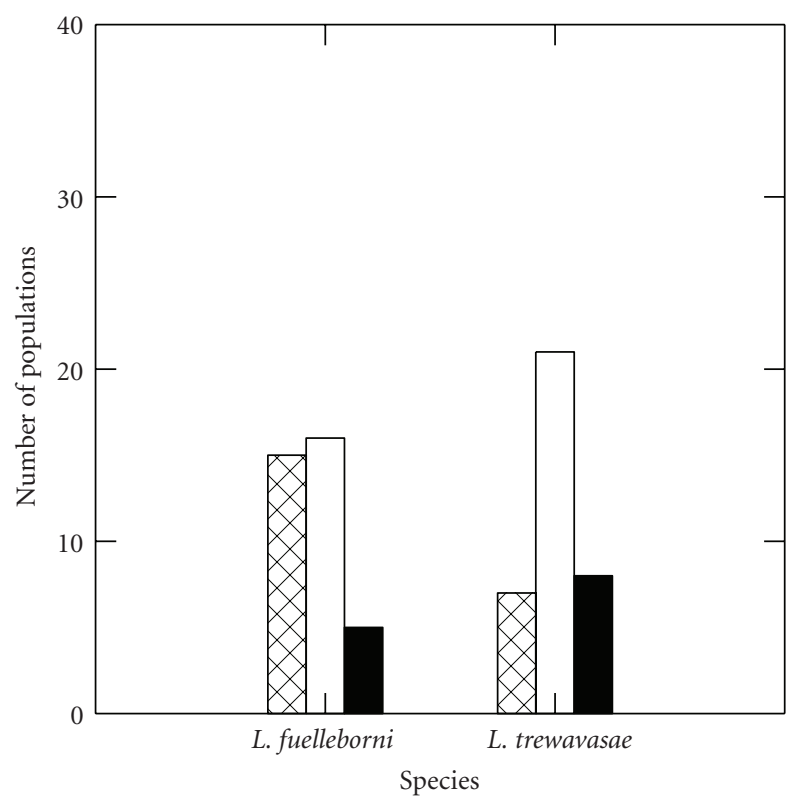

Habitat type

$\square$ Island

$\square$ Mainland

- Rock/reef

(a)

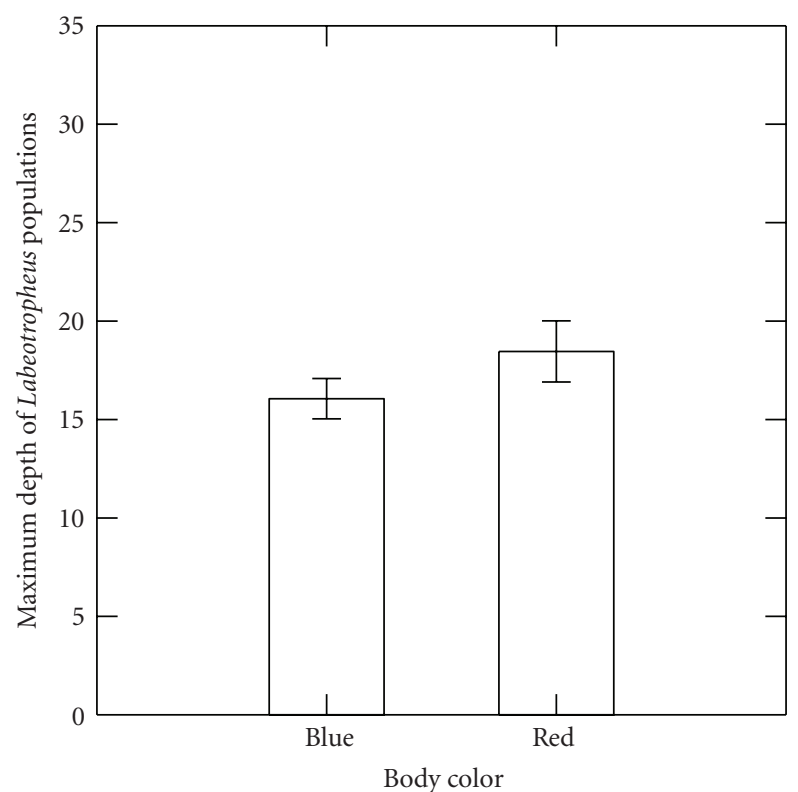

(b)

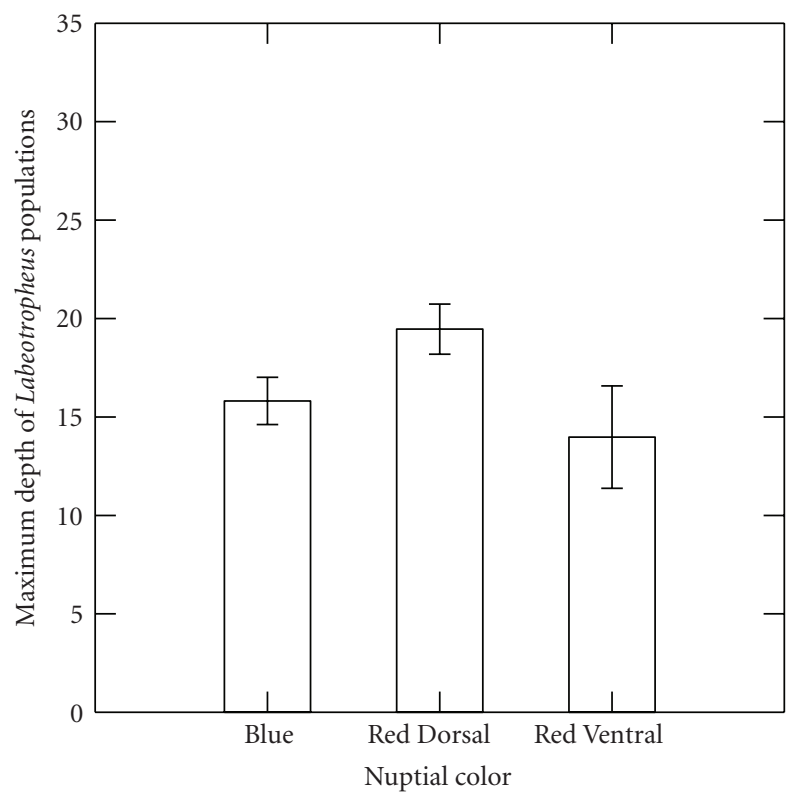

(c)

Figure 3: Predictive relationships between environmental variables and Labeotropheus color patterns. (a) Frequency of Labeotropheus species at each habitat type. (b) Maximum depths at which each Labeotropheus body color type is found. (c) Maximum depths at which Labeotropheus nuptial color types are found.

This finding suggests that male nuptial coloration is a signal of specific status in the Labeotropheus and is thus probably an important component of the reproductive isolating mechanisms or mate-recognition systems between sympatric pairs of Labeotropheus. Further, male mbuna do not tolerate similarly colored opponents in their territories [17], so the different male coloration between the Labeotropheus species at locations where they are sympatric could also be the result of intrasexual selection.

The results presented herein strongly suggest that the nuptial color patterns of male Labeotropheus may be the result of naturally and sexually selected constraints. This 


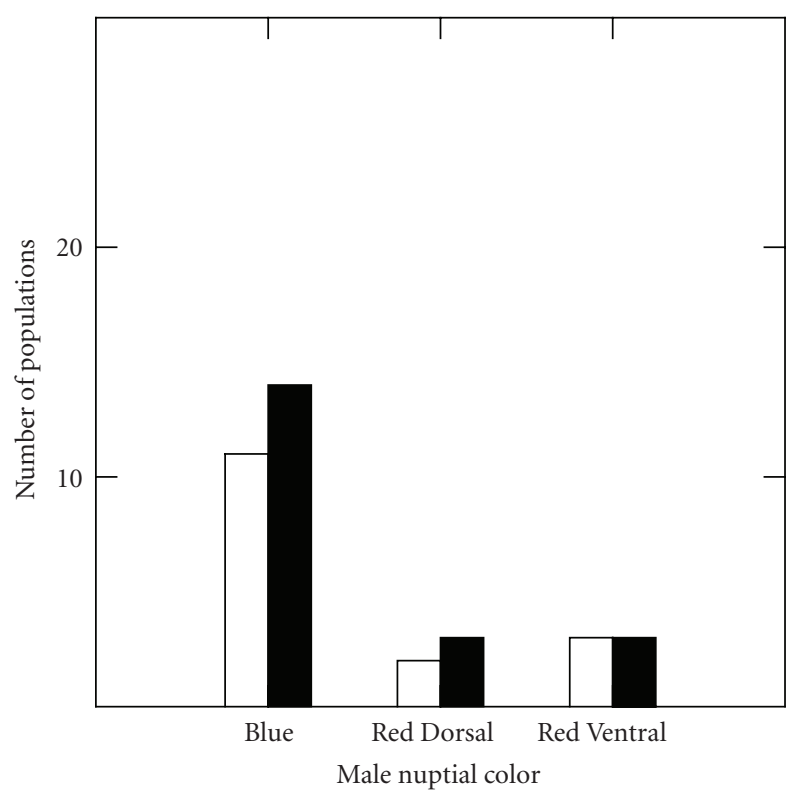

Number of Labeotropheus species present $\square 1$ $\square 2$

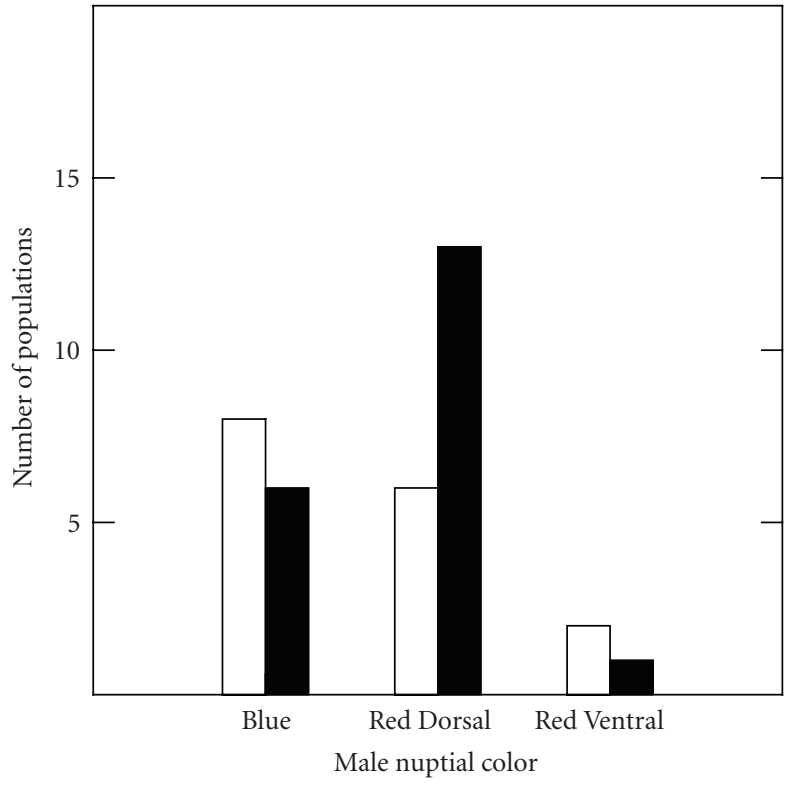

Number of Labeotropheus species present $\square 1$

(a)

(b)

Figure 4: Frequency of nuptial color types at sympatric and allopatric populations of Labeotropheus. (a) L. fuelleborni. (b) L. trewavasae. While the proportions of nuptial colors displayed by $L$. fuelleborni remain relatively consistent whether found with or without $L$. trewavasae, note the marked increase of Red Dorsal coloration in populations of L. trewavasae sympatric with L. fuelleborni.

TABLE 5: Standardized between-set regression coefficients.

\begin{tabular}{lcccc}
\hline & Species (1) & Nuptial Color (1) & Nuptial Color (2) & Body Color (1) \\
\hline Latitude & -0.021 & 0.107 & -0.346 & $-0.409^{* * *}$ \\
Longitude & -0.049 & -0.122 & -0.061 & -0.030 \\
Minimum depth & $-0.345^{* * *}$ & -0.341 & 0.001 & -0.071 \\
Maximum depth & $0.395^{* *}$ & $0.661^{*}$ & -0.479 & $0.415^{* *}$ \\
Modal depth & $0.819^{* * *}$ & -0.151 & 0.294 & -0.281 \\
Habitat (1) & -0.006 & -0.040 & -0.119 & -0.001 \\
Habitat (2) & $-0.329^{* * *}$ & -0.027 & -0.115 & -0.136 \\
Number of Labeotropheus species & 0.109 & $0.243^{*}$ & -0.129 & 0.010 \\
\hline
\end{tabular}

${ }^{*} P \leq .05 ; * * P \leq .01 ; * * * P \leq .001$.

conclusion, while in definite need of further confirmation and refinement through gathering new field and laboratory data, serves to underline the equivocal nature of the results of similar studies. Thus, as Dalton et al. [25] suggest, putative associations between male nuptial coloration and environmental variables in the haplochromine cichlids deserve much more attention, especially since much has been written regarding the importance of male color pattern and speciation in these fishes. As such, exacting measurements of the spectral environment made at both shallow and deep-dwelling populations of Labeotropheus would aid in understanding the conditions in which these signals and receivers coevolved. Further, while laboratory studies have confirmed that male coloration is important in sexual selection, in situ studies of natural mate choice tendencies or experimental manipulations of inter- and intrasexual encounters under natural lighting conditions could be very useful in further untangling the roles of natural and sexual selection in the evolution of male coloration.

\subsection{A Postscript: Why Red? Why Not "One Fish, Two Fish, Blue Fish....Bluer Fish"?}

Red or other carotenoid-based colors present a number of challenges for fishes. In many cases, such pigments are derived from dietary sources, necessitating a search for the foods that will yield the dietary precursors to synthesize these pigments [46]. The attenuation of long-wavelength light with depth presents an additional challenge; if a fish wants to be cryptic or to have a "private," short-range signal, red 


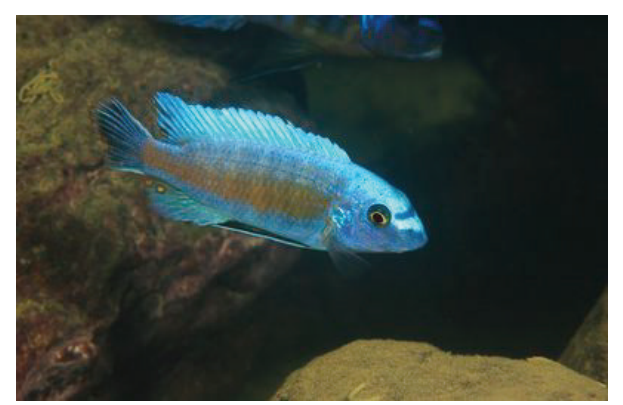

(a)

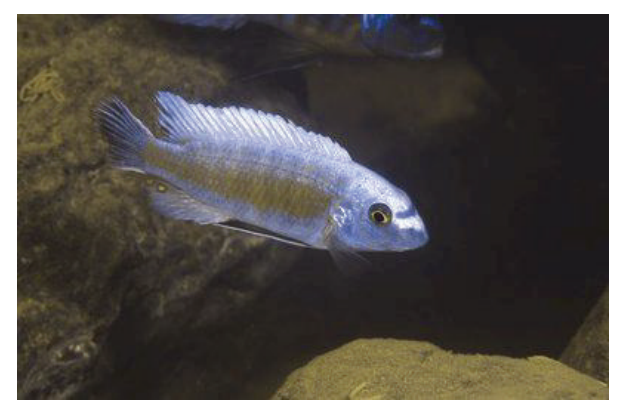

(b)

FIGURE 5: A comparison between the appearance of a predominantly carotenoid-based Labeotropheus color pattern as seen by a trichromatic human (a) and a protanopic human (b). While largely heuristic, this figure illustrates that even without a longwavelength-sensitive photoreceptor, a protanopic human or mbuna (like a Labeotropheus) could still perceive the contrast between the carotenoid patch at midbody and the rest of the fish. It should be noted that Figure 4(b) does not take into account either the ultraviolet-sensitive photoreceptor of the Labeotropheus or the attenuation of red and orange light at the depths at which this fish, a L. trewavasae from Manda, Tanzania, would typically be found. The original photo (a) is generously provided by Ad Konings/Cichlid Press, and the Daltonized photo (b) was produced from the original using the Vischeck algorithm, available at http://www.vischeck.com.

coloration might be a good option. But what about fish that visually search for mates and for whom nuptial color signals are of extraordinary importance in identifying mates or even competitors (e.g., [17])? Further, for fish like many of the mbuna, and the Labeotropheus in particular, that lack a long-wavelength-sensitive photoreceptor [25, 47], the use of carotenoid-based pigments is even more puzzling; why utilize pigments to which your visual system is insensitive? The answer most likely has to do with within-pattern contrast.

Pauers et al. [16] demonstrated that females of L. c.f. fuelleborni "Katale" consistently preferred males with the highest degree of contrast among the various color pattern elements present on the flanks of the fish. The males of this population are an example of a Red Ventral nuptial color pattern, with a prominent orange patch on their sides below their lateral line; in some individuals, this patch might comprise more than $67 \%$ of the surface area of their flanks. Further, Dalton et al. [25] found that many of the mbuna species they examined also had a high degree of contrast within their color patterns, including species that, like the Labeotropheus, lack a long-wavelength-sensitive photoreceptor. While anthropomorphism is always dangerous, these fish may see the world, in part, like a protanopic human, who also lacks a long-wavelength-sensitive photoreceptor, but sees reds as a different color entirely (Figure 5); indeed, the inability to discriminate amongst red and reddish hues may be the reason why there are so few examples of true, saturated reds in the Labeotropheus and other mbuna. Nonetheless, as long as an observing fish's percept of the carotenoid pigment patch contrasts with the percept of the neighboring patch or patches, the overall integrity of the signal is maintained, despite the lack of sensitivity to long-wavelength colors.

\section{Acknowledgments}

Robert Henderson and Ellen Censky (MPM) provided office space, computer equipment, and time to allow the completion of this paper. Jay Neitz (Medical College of Wisconsin, University of Washington) provided postdoctoral support and much instruction about the biology and ecology of vision. This paper benefited greatly from discussions with Harvey Bootsma, Jeff McKinnon, and Tyrone Spady. Joseph Boxhorn and Randy Mooi provided many helpful comments on early drafts. Tim Ehlinger, Craig Berg, Lori Schacht DeThorne, and Liz O'Grady commented on early presentations of the data herein. Chuck Wimpee provided a key reference.

\section{References}

[1] J. A. Endler, "On the measurement and classification of colour in studies of animal colour patterns," Biological Journal of the Linnean Society, vol. 41, no. 4, pp. 315-352, 1990.

[2] K. L. Barry and C. W. Hawryshyn, "Spectral sensitivity of the Hawaiian saddle wrasse, Thalassoma duperrey, and implications for visually mediated behaviour on coral reefs," Environmental Biology of Fishes, vol. 56, no. 4, pp. 429-442, 1999.

[3] J. A. Endler, "The color of light in forests and its implications," Ecological Monographs, vol. 63, no. 1, pp. 1-27, 1993.

[4] K. L. Barry and C. W. Hawryshyn, "Effects of incident light and background conditions on potential conspicuousness of Hawaiian coral reef fish," Journal of the Marine Biological Association of the United Kingdom, vol. 79, no. 3, pp. 495-508, 1999.

[5] J. M. Macedonia, "Habitat light, colour variation, and ultraviolet reflectance in the Grand Cayman anole, Anolis conspersus," Biological Journal of the Linnean Society, vol. 73, no. 3, pp. 299-320, 2001.

[6] J. A. Endler, "Signals, signal conditions, and the direction of evolution," American Naturalist, vol. 139, pp. S125-S153, 1992.

[7] R. C. Fuller, "Lighting environment predicts the relative abundance of male colour morphs in bluefin killifish (Lucania goodei) populations," Proceedings of the Royal Society B, vol. 269, no. 1499, pp. 1457-1465, 2002.

[8] N. J. Marshall, "Communication and camouflage with the same "bright" colours in reef fishes," Philosophical Transactions of the Royal Society B, vol. 355, no. 1401, pp. 1243-1248, 2000. 
[9] E. Warrant, "The eyes of deep-sea fishes and the changing nature of visual scenes with depth," Philosophical Transactions of the Royal Society B, vol. 355, no. 1401, pp. 1155-1159, 2000.

[10] S. Johnsen, "Cryptic and conspicuous coloration in the pelagic environment," Proceedings of the Royal Society B, vol. 269, no. 1488, pp. 243-256, 2002.

[11] J. A. Endler, "Natural selection on color patterns in Poecilia reticulata," Evolution, vol. 34, pp. 76-91, 1980.

[12] S. Holzberg, "A field and laboratory study of the behaviour and ecology of Pseudotropheus zebra (Boulenger), an endemic cichlid of Lake Malawi (Pisces: Cichlidae)," Zeitschrift für Zoologische Systematik und Evolutionsforschung, vol. 16, pp. 171-187, 1978.

[13] W. J. Dominey, "Effects of sexual selection and life history on speciation: species flocks in African cichlids and Hawaiian Drosophila," in Evolution of Fish Species Flocks, A. A. Echelle and I. Kornfield, Eds., pp. 231-250, University of Maine at Orono Press, Orono, Me, USA, 1984.

[14] O. Seehausen, F. Witte, J. J. M. van Alphen, and N. Bouton, "Direct mate choice maintains diversity among sympatric cichlids in Lake Victoria," Journal of Fish Biology, vol. 53, pp. 37-55, 1998.

[15] M. E. Knight and G. F. Turner, "Laboratory mating trials indicate incipient speciation by sexual selection among populations of the cichlid fish Pseudotropheus zebra from Lake Malawi," Proceedings of the Royal Society B, vol. 271, no. 1540, pp. 675-680, 2004.

[16] M. J. Pauers, J. S. McKinnon, and T. J. Ehlinger, "Directional sexual selection on chroma and within-pattern colour contrast in Labeotropheus fuelleborni," Proceedings of the Royal Society B, vol. 271, no. 6, supplement, pp. S444-S447, 2004.

[17] M. J. Pauers, J. M. Kapfer, C. E. Fendos, and C. S. Berg, "Aggressive biases towards similarly coloured males in Lake Malawi cichlid fishes," Biology Letters, vol. 4, no. 2, pp. 156$159,2008$.

[18] J. C. Deutsch, "Colour diversification in Malawi cichlids: evidence for adaptation, reinforcement or sexual selection?" Biological Journal of the Linnean Society, vol. 62, no. 1, pp. 114, 1997.

[19] O. Seehausen, P. J. Mayhew, and J. J. M. van Alphen, "Evolution of colour patterns in East African cichlid fish," Journal of Evolutionary Biology, vol. 12, no. 3, pp. 514-534, 1999.

[20] O. Seehausen and D. Schluter, "Male-male competition and nuptial-colour displacement as a diversifying force in Lake Victoria cichlid fishes," Proceedings of the Royal Society B, vol. 271, no. 1546, pp. 1345-1353, 2004.

[21] K. A. Young, J. M. Whitman, and G. F. Turner, "Secondary contact during adaptive radiation: a community matrix for Lake Malawi cichlids," Journal of Evolutionary Biology, vol. 22, no. 4, pp. 882-889, 2009.

[22] T. Goldschmidt, "Egg mimics in haplochromine cichlids (Pisces, Perciformes) from Lake Victoria," Ethology, vol. 88, pp. 177-190, 1991

[23] D. M. McElroy, I. Kornfield, and J. Everett, "Coloration in African cichlids: diversity and constraints in Lake Malawi endemics," Netherlands Journal of Zoology, vol. 41, no. 4, pp. 250-268, 1991.

[24] O. Seehausen, Y. Terai, I. S. Magalhaes et al., "Speciation through sensory drive in cichlid fish," Nature, vol. 455, no. 7213, pp. 620-626, 2008.

[25] B. E. Dalton, T. W. Cronin, N. J. Marshall, and K. L. Carleton, "The fish eye view: are cichlids conspicuous?" Journal of Experimental Biology, vol. 213, no. 13, pp. 2243-2255, 2010.

[26] W. R. A. Muntz, "Visual pigments of cichlid fishes from Malawi," Vision Research, vol. 16, no. 9, pp. 897-903, 1976.
[27] T. C. Spady, O. Seehausen, E. R. Loew, R. C. Jordan, T. D. Kocher, and K. L. Carleton, "Adaptive molecular evolution in the opsin genes of rapidly speciating cichlid species," Molecular Biology and Evolution, vol. 22, no. 6, pp. 1412-1422, 2005.

[28] Y. Terai, O. Seehausen, T. Sasaki et al., "Divergent selection on opsins drives incipient speciation in Lake Victoria cichlids," PLoS Biology, vol. 4, no. 12, article e433, 2006.

[29] K. L. Carleton, J. W. L. Parry, J. K. Bowmaker, D. M. Hunt, and O. Seehausen, "Colour vision and speciation in Lake Victoria cichlids of the genus Pundamilia," Molecular Ecology, vol. 14, no. 14, pp. 4341-4353, 2005.

[30] E. Ahl, "Einige neue Fische der Familie Cichlidae aus dem Nyassasee," Sitzungberichte der Gesellschaft Naturforschender Freunde zu Berlin, vol. 1926, pp. 51-62, 1927.

[31] A. J. Ribbink, B. A. Marsh, A. C. Marsh, A. C. Ribbink, and B. J. Sharp, "A preliminary survey of the cichlid fishes of rocky habitats in Lake Malawi," South African Journal of Zoology, vol. 18 , no. 3, pp. 149-310, 1983.

[32] A. J. Ribbink, A. C. Marsh, B. A. Marsh, and B. J. Sharp, "The zoogeography, ecology and taxonomy of the genus Labeotropheus Ahl, 1927, of Lake Malawi (Pisces: Cichlidae)," Zoological Journal of the Linnean Society, vol. 79, no. 3, pp. 223-243, 1983.

[33] A. Konings, Malawi Cichlids in Their Natural Habitat, Cichlid Press, El Paso, Tex, USA, 4th edition, 2007.

[34] M. J. Pauers, "Species concepts, speciation, and taxonomic change in the Lake Malawi mbuna, with special reference to the genus Labeotropheus Ahl 1927 (Perciformes: Cichlidae)," Reviews in Fish Biology and Fisheries, vol. 20, no. 2, pp. 187202, 2010

[35] M. E. Arnegard, J. A. Markert, P. D. Danley, J. R. Stauffer Jr., A. J. Ambali, and T. D. Kocher, "Population structure and colour variation of the cichlid fish Labeotropheus fuelleborni Ahl along a recently formed archipelago of rocky habitat patches in southern Lake Malawi," Proceedings of the Royal Society B, vol. 266, no. 1415 , pp. 119-130, 1999.

[36] G. Fryer and T. D. Iles, The Cichlid Fishes of the Great Lakes of Africa, Oliver \& Boyd, Edinburgh, Scotland, 1972.

[37] M. J. Pauers, T. J. Ehlinger, and J. S. McKinnon, "Female and male visually-based mate preferences are consistent with reproductive isolation between populations of the Lake Malawi endemic Labeotropheus fuelleborni," Current Zoology, vol. 56, no. 1, pp. 65-72, 2010.

[38] L. DeMason, A Guide to the Tanzanian Cichlids of Lake Malawi, National Art Publishing, Ft. Myers, Fla, USA, 1995.

[39] A. Konings, Malawi Cichlids in Their Natural Habitat, Cichlid Press, El Paso, Tex, USA, 2nd edition, 1995.

[40] A. Spreinat, Aqualex Catalog: Cichlids from Lake Malawi, Dahne Verlag GmbH, Ettlingen, Germany, 1997.

[41] O. Seehausen, J. J. M. Van Alphen, and F. Witte, "Can ancient colour polymorphisms explain why some cichlid lineages speciate rapidly under disruptive sexual selection?" Belgian Journal of Zoology, vol. 129, no. 1, pp. 43-60, 1999.

[42] J. Cohen and P. Cohen, Applied Multiple Regression/Correlation Analysis for the Behavioral Sciences, Lawrence Erlbaum Associates, Hillsdale, NJ, USA, 2nd edition, 1983.

[43] J. Cohen and L. Wilkinson, "Set and canonical correlation," SYSTAT 10: Statistics II, SPSS, Inc., Chicago, Ill, USA, 2000.

[44] C. J. Allender, O. Seehausen, M. E. Knight, G. F. Turner, and N. Maclean, "Divergent selection during speciation of Lake Malawi cichlid fishes inferred from parallel radiations in nuptial coloration," Proceedings of the National Academy of Sciences of the United States of America, vol. 100, no. 2, pp. 14074-14079, 2003.

[45] P. F. Smith and I. Kornfield, "Phylogeography of Lake Malawi cichlids of the genus Pseudotropheus: significance of allopatric 
colour variation," Proceedings of the Royal Society B, vol. 269, no. 1509, pp. 2495-2502, 2002.

[46] J. Lindström, T. W. Pike, J. D. Blount, and N. B. Metcalfe, "Optimization of resource allocation can explain the temporal dynamics and honesty of sexual signals," American Naturalist, vol. 174, no. 4, pp. 515-525, 2009.

[47] K. L. Carleton, F. I. Hárosi, and T. D. Kocher, "Visual pigments of African cichlid fishes: evidence for ultraviolet vision from microspectrophotometry and DNA sequences," Vision Research, vol. 40, no. 8, pp. 879-890, 2000. 

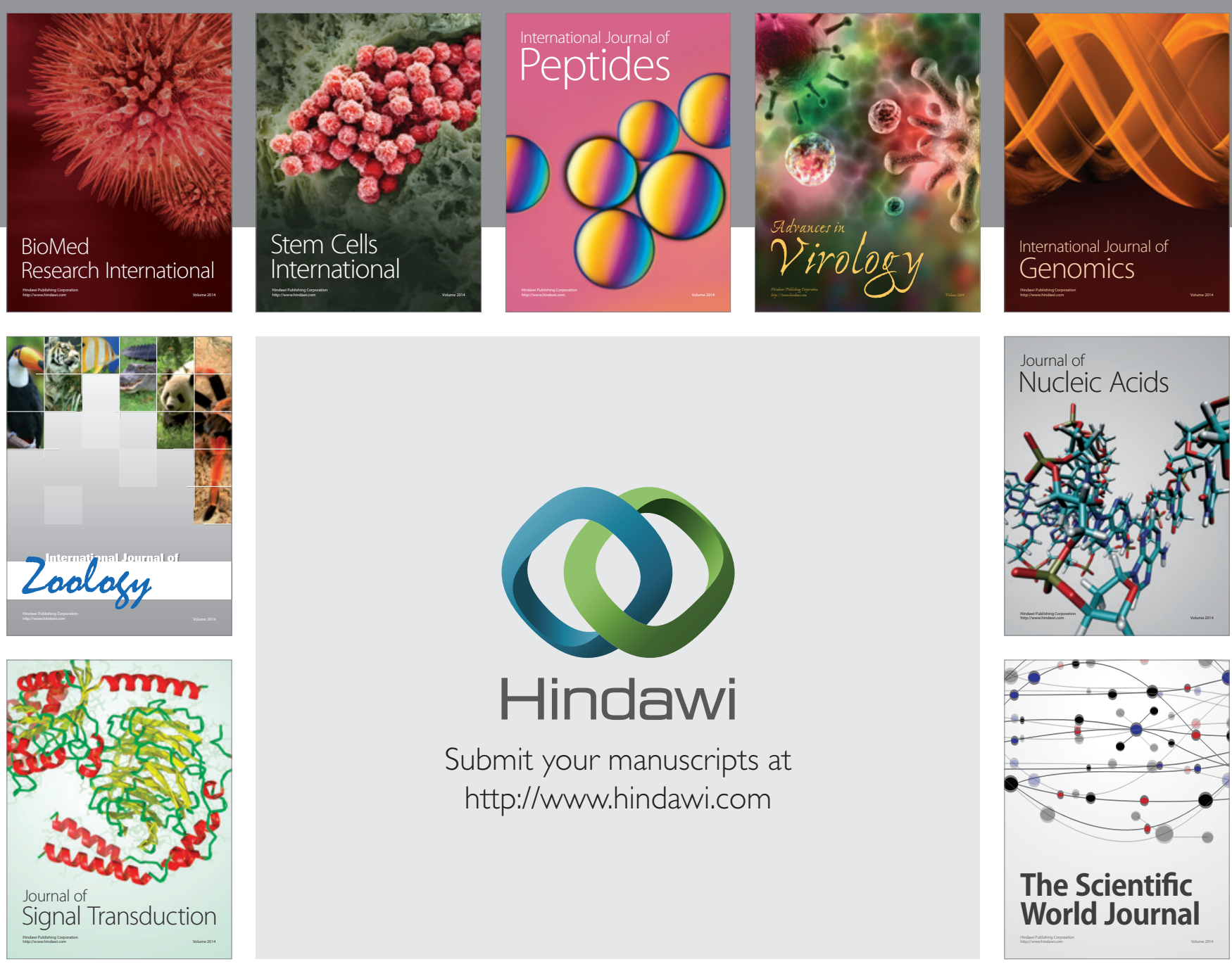

Submit your manuscripts at

http://www.hindawi.com
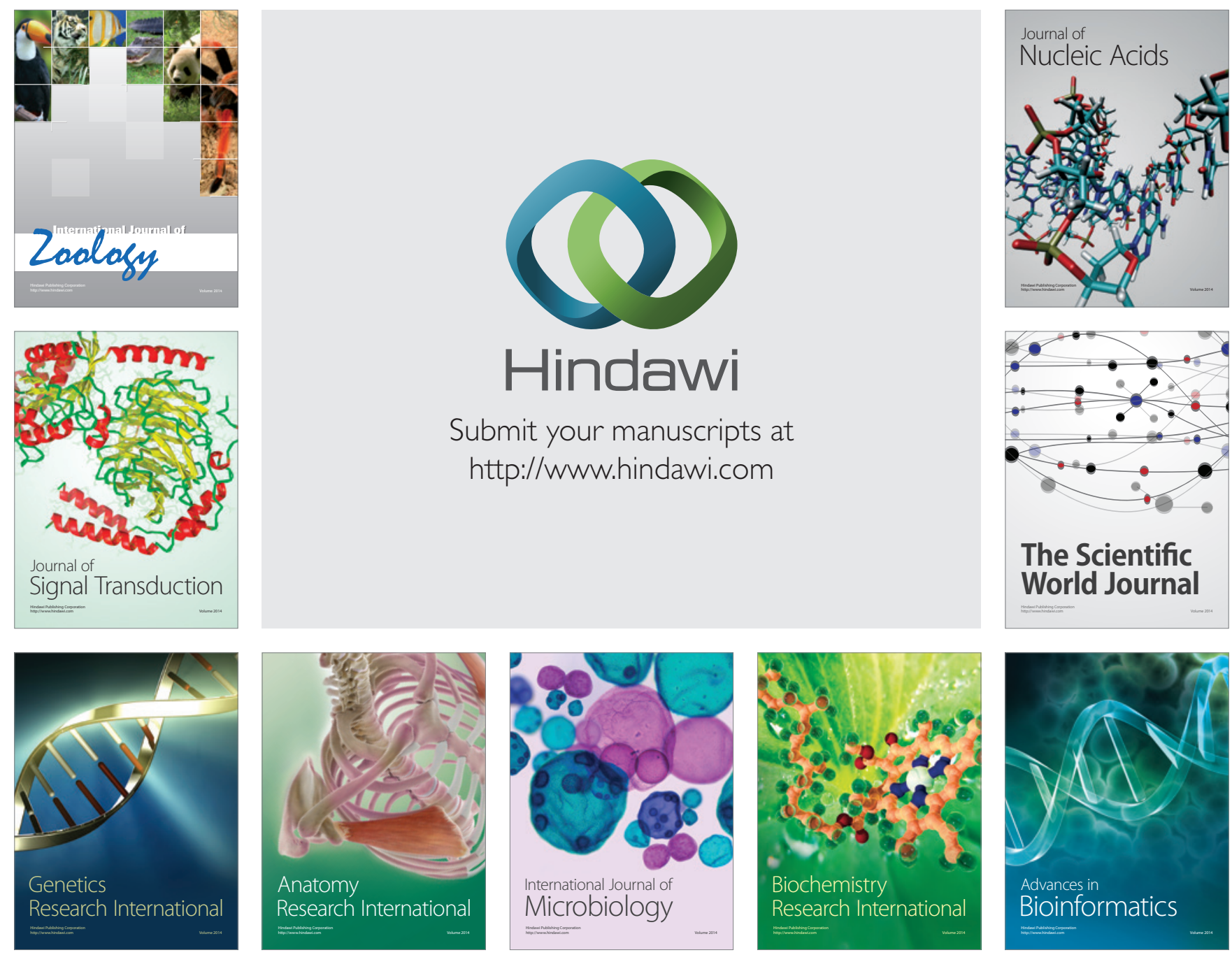

The Scientific World Journal
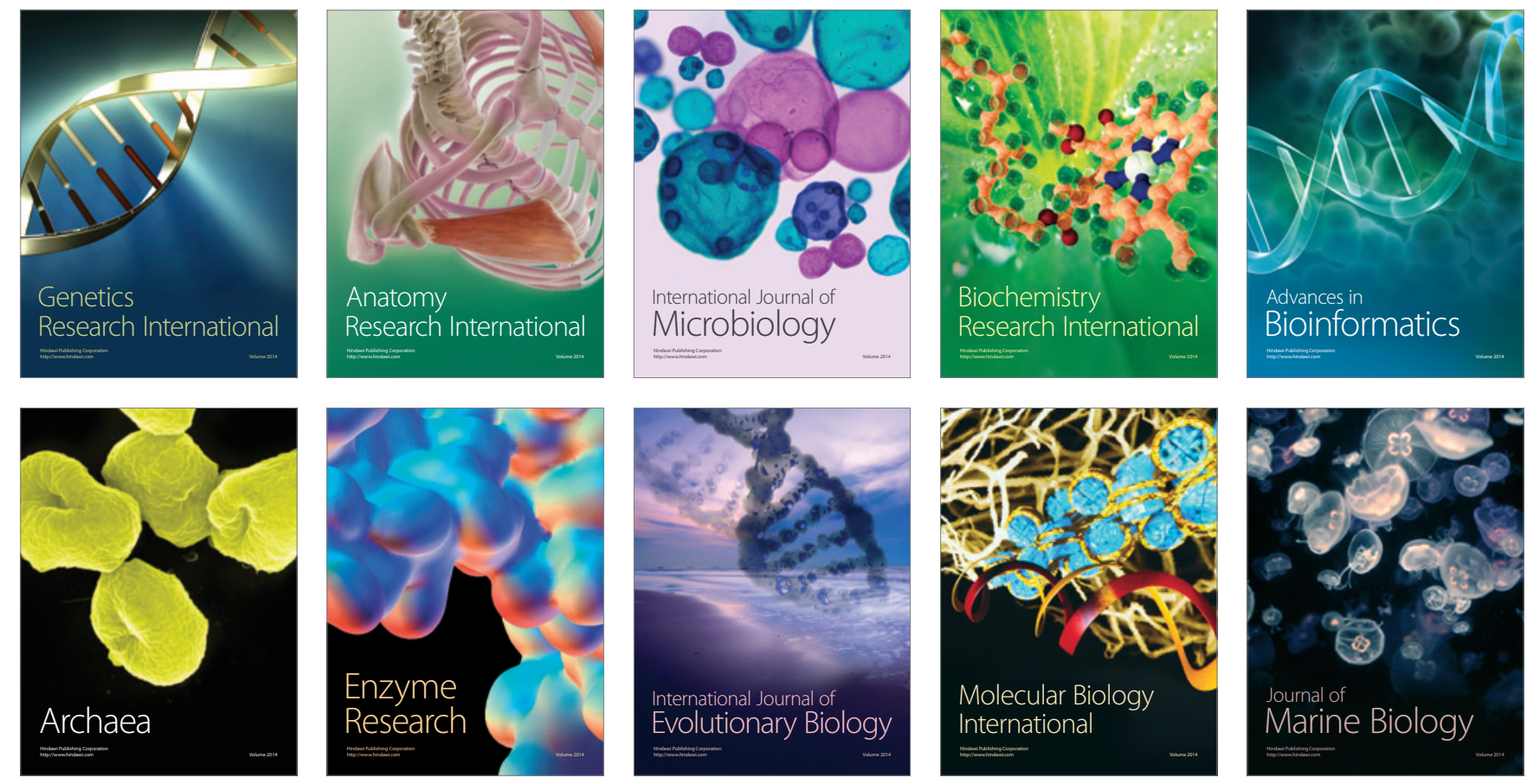